\title{
A Farra do Boi: humanidade, animalidade e as sensibilidades jurídicas em uma decisão judicial
}

\author{
Farra do Boi: humanity, animality and legal sensibilities in a judicial decision
}

\author{
João Francisco Kleba Lisboa ${ }^{1}$ \\ Universidade Federal do Paraná, Curitiba, PR, Brasil
}

\begin{abstract}
Resumo: A farra do boi, como ficou conhecida a prática tradicional de algumas comunidades pesqueiras do litoral catarinense, atualmente proibida pela justiça sob alegação de maus-tratos aos animais, é um caso propício para observar os contrastes entre diferentes sensibilidades jurídicas, assim como as profundas diferenças entre o fazer antropológico e o trabalho dos julgadores. Para isso, o artigo busca se fundamentar em noções que acompanham a formação moderna do pensamento ocidental, como as classificações dicotômicas entre bárbaro e civilizado, natureza e cultura, rural e urbano, chegando à Constituição Federal e seus artigos, que garantem a proteção tanto da cultura quanto do meio ambiente.
\end{abstract}

Palavras-chave: Farra do Boi. Sensibilidade Jurídica. Constituição Federal.

\begin{abstract}
The farra do boi, as become known the traditional practice of some fishing communities on Santa Catarina coast, which is currently banned by justice on the grounds of animal abuse, is a propitious case to observe the contrasts between different legal sensibilities, as well as the profound differences between the anthropological making and the work of the judges. For this, the article seeks to be based on notions that accompany the modern formation of Western thought, such as the dualistic classification between barbarian and civilized, nature and culture, rural and urban, reaching the Federal Constitution and its articles, that guarantee the protection of both culture and environment.
\end{abstract}

Keywords: Farra do Boi. Legal Sensibilities. Federal Constitution.

Recebido em: 26/08/2019

Revisado em: 27/04/2020

Aprovado em: 27/10/2020 


\section{Introdução}

Quem nos salva da bondade dos bons?

(AGOSTINHO RAMALHO MARQUES NETO)

Com este ensaio, pretende-se contribuir para um debate cuja relevância extrapolou a esfera local - o litoral de Santa Catarina, região em que nasci e me criei - para atingir abrangência nacional e uma dimensão ética, por assim dizer, universal. Refiro-me à prática daquilo que os nativos locais chamam de "boi do campo", ou "boi no pasto", ou mesmo apenas "boi" ou "farra", e que ficou conhecida nacionalmente como "farra do boi". Essa prática decorre de uma tradição cultural trazida pelos açorianos que colonizaram o litoral do estado em meados do século XVIII e que atualmente é proibida pela justiça, após julgamento de grande repercussão na mais alta corte do país, o Supremo Tribunal Federal (STF). Apesar de proibida, a farra do boi continua sendo praticada até os dias de hoje, principalmente durante os períodos de Páscoa e final de ano, em meio às tentativas das autoridades locais de reprimi-la. $\mathrm{O}$ assunto passou a tomar as páginas de jornais nos anos de 1970, sendo que o auge da "polêmica" em torno da farra se deu na década seguinte, quando recebeu grande destaque em veículos nacionais como $O$ Estado de São Paulo, Folha de São Paulo e Revista Veja, sendo que esta última o elegeu como um dos assuntos do ano de 1988 (FLORES, 1998, p. 58-61). De certa forma, os posicionamentos em torno da farra do boi polarizaram-se entre um discurso de repúdio aos maus-tratos contra os animais (ou defesa dos direitos dos animais) e um discurso de direito à manutenção da cultura tradicional (ou defesa da farra-do-boi). No campo jurídico, esse embate encontrou seus dispositivos correspondentes na Constituição Federal de 1988, com os artigos 215 e 216 de um lado e 225 e seus parágrafos do outro. Estava em jogo a proibição ou não de um costume local em que o boi era sacrificado em uma espécie de festa comunitária após ser solto em espaço aberto para que as pessoas se aventurassem a chegar perto do animal arredio. Ofereço aqui uma abordagem que faz uso de referenciais teóricos da antropologia 
jurídica, no intuito de tentar compreender as diferentes sensibilidades jurídicas e valores morais envolvidos na questão.

\section{Bárbaros e Civilizados, Humanos e Animais}

A mobilização que ganhou amplitude nacional - e internacional contra a prática da farra do boi como um costume intrinsecamente cruel, frequentemente desviou-se para acusações contra os seus praticantes, buscando, também nestes, qualidades intrínsecas reprováveis. Logo essas denúncias assumiram uma configuração que se organizava sob a gramática da oposição civilização vs. barbárie, e os praticantes da farra foram retratados como "bestas", "selvagens" ou "primitivos". Se, a princípio há uma contradição explícita, pois os defensores dos animais usavam justamente a condição animal como uma característica desqualificadora para atacar os farristas, fica claro também o tom evolucionista das críticas formuladas, referindo-se à farra do boi como um atraso inaceitável para os dias atuais:

Não é de admirar, portanto, que a farra do boi tenha sido descrita tantas vezes como um ato de selvageria e os que a praticam, como agentes de "instintos primitivos", "feras em figura de gente", "bestas humanas", de "mentalidade repugnante", de "raciocínio primário", "excitados" e que "aparentemente, ainda não chegou ao século XX, nem ao século XIX, nem ao XVIII, nem ao XVII". [...] Se a piedade, a compaixão e a relutância em infligir dor aos bichos são identificadas como emoções características dos civilizados, por referência a estes, os "outros", os que brincam com o boi, encontram-se "ainda" em estágios pouco desenvolvidos. Não evoluíram no tempo e comprometem o "progresso" histórico tido muitas vezes, como uma trajetória necessária do ser humano, com uma única direção. Brigite Bardot escreveu ao Ministro da Justiça que "O Brasil não pode se considerar um civilizado permitindo esse ritual macabro". (FLORES, 1998, p. 73)

Chama a atenção, nos depoimentos colhidos por Maria Bernardete Ramos Flores acima citados, a sequência cronológica regressiva, do sé- 
culo XX ao século XVII, como que a empurrar os farristas para longe do presente, em direção a um passado cada vez mais distante ${ }^{1}$. Tem-se aí não apenas uma alusão ao tempo meramente quantificável, mas uma série de períodos sobre os quais a dita civilização ocidental se formou: o século XX com seus movimentos modernistas e declarações universais de direitos, o século XIX com seu republicanismo e cientificismo, ao século XVIII com seu iluminismo e as revoluções francesa e americana, ao século XVII e a centralização do poder do Estado. De alguma forma, a afirmação de que "essa gente não chegou à idade moderna" não está totalmente errada, não no sentido de que haja uma população atrasada no tempo devido a falhas no processo de evolução histórica, mas sim de que todas essas conquistas da política moderna de fato não alcançaram a farra do boi a ponto de conseguir suprimi-la. Há realmente um lapso entre os farristas e os defensores dos direitos dos animais, mas este não é um lapso evolutivo e sim uma distância formada pela existência de valores culturais diferentes, ou melhor, pela sobrevivência, no litoral de Santa Catarina, em pleno século XXI, de uma festividade - que inclui, entre outras coisas, uma dimensão normativa própria - que não é abarcada pelas práticas e valores modernos, sendo mesmo por estes repudiada e combatida.

A filosofia política moderna, sobretudo com Thomas Hobbes, construiu-se nos moldes da superação do estado de natureza a partir da instituição de uma comunidade política, através do contrato social. É apenas com a criação da Civitas, "que não é senão um homem artificial" (HOBBES, 1993, p. 61), que os homens conseguiriam impor limites às suas paixões e apetites, pois “[...] se não for instituído um poder suficientemente grande para nossa segurança, cada um confiará, e poderá legitimamente confiar, apenas em sua própria força e capacidade, como proteção contra todos os outros" (HOBBES, 1993, p. 73). Essa separação

\footnotetext{
${ }^{1}$ Tal movimento remete ao oposto daquele a que é forçado o famoso "anjo da história" de Walter Benjamin. O anjo de Benjamin é arrastado para o futuro pelo vendaval do progresso e, como está voltado para trás, afasta-se do passado enquanto olha para ele, "[...] uma catástrofe sem fim, que incessantemente acumula ruínas sobre ruínas e lhas lança aos pés" (BENJAMIN, 2013, p. 14). Já nossos nativos são atirados para o passado a partir do presente, o que, em uma mudança de perspectiva, seria como transformá-los também em ruínas.
} 
entre dois mundos, o da natureza (como guerra de todos contra todos) e o da cultura (ou sociedade/civilização/Estado) ${ }^{2}$ deu-se também em termos de uma oposição animalidade versus humanidade. Como expôs Louis Dumont (1985, p. 99):

Se tentarmos captar o âmago da doutrina, resumir para nosso uso a imagem do "homem" desenhada por Hobbes e vê-la em relação com a constituição da Commonwealth, é difícil fugir à impressão de um dualismo entre as paixões e a razão, entre uma face animal e uma face racional. E, com efeito, não é a contradição entre as duas que torna necessária a passagem ao estado político, a entrada em sujeição? De fato, o que diferencia no Leviatã o homem do animal é a língua e a razão fundamentada na língua. Com essa reserva, o dualismo sustenta-se: a racionalidade é concedida ao homem sob uma forma impura, misturada de animalidade, e só se expandirá em pura racionalidade com a construção de uma Commonwealth artificial. Admitir, com Aristóteles, que o homem é naturalmente social e (ou) político, seria proibi-lo de atingir a racionalidade pura.

De fato, esse dualismo entre paixão e razão que se encontra nos contratualistas, como Hobbes, reflete outro dilema da visão ocidental so-

\footnotetext{
${ }^{2}$ A separação moderna entre natureza e cultura a que me refiro é aquela que o antropólogo Bruno Latour chamou de trabalho de "purificação" operado pelas garantias mútuas de uma "Constituição" moderna. Ocorre que, para Latour, tal separação teria tornado inviável a compreensão do mundo, uma vez que ambas as partes necessitam uma da outra para funcionar: "Este poder oferece uma garantia igualmente capital: são os homens e apenas os homens que constroem a sociedade e que decidem livremente acerca de seu destino. [...] Se, assim como a filosofia política moderna, considerarmos estas duas garantias separadamente, elas continuam a ser incompreensíveis. Se a natureza não é feita pelos homens nem para eles, então ela continua a ser estrangeira, para sempre longínqua e hostil. Sua própria transcendência nos esmaga ou a torna inacessível. Simetricamente, se a sociedade é feita apenas pelos homens e para eles, o Leviatã, criatura artificial da qual somos ao mesmo tempo a forma e a matéria, não seria capaz de se sustentar. Sua própria imanência iria dissipá-lo imediatamente na guerra de cada um contra os outros. Mas não é separadamente que devemos considerar estas duas garantias constitucionais, a primeira assegurando a não-humanidade da natureza e a segunda, a humanidade do social. Elas foram criadas juntas. Sustentam-se mutuamente. A primeira e a segunda garantias servem de contrapeso mútuo, de checks and balances. Elas são apenas dois ramos do mesmo governo" (LATOUR, 1994, p. 36).
} 
bre o próprio homem e a natureza: a dupla condição humana de ser, ao mesmo tempo, uma espécie animal e algo totalmente oposto a um animal. Para o Ocidente, mesmo após Darwin ter demonstrado o vínculo entre todos os seres vivos, apenas os homens são filosoficamente sujeitos morais e, portanto, pessoas. O que concede tal exclusividade à espécie Homo sapiens seria o fato de esta, e apenas ela, ser dotada de "razão e consciência”. Como expõe Tim Ingold (1995, p. 8):

Temos agora condições de solucionar um paradoxo situado no cerne do pensamento ocidental, que afirma, com igual segurança, tanto que os seres humanos são animais quanto que a animalidade é o exato oposto da humanidade. Um ser humano é um indivíduo pertencente a uma espécie; existir como ser humano é existir como pessoa. No primeiro sentido, o conceito de humanidade refere-se a uma categoria biológica (Homo sapiens); no segundo, aponta para uma condição moral (de pessoa). O fato de que empregamos a mesma palavra "humano" para ambos os sentidos reflete a convicção profundamente arraigada de que todos os indivíduos pertencentes à espécie humana - e exclusivamente estes - podem ser pessoas, ou, dito de outra forma, que a condição de pessoa depende do pertencimento à categoria taxionômica. Como postula o Artigo Primeiro da Declaração Universal dos Direitos do Homem: "Todos os seres humanos são dotados de razão e consciência." Fica implícito, portanto, que os animais não-humanos não o são"

Tim Ingold demonstra o quanto a nossa definição “[...] de pessoa como uma prerrogativa dos seres humanos, é tão dependente da visão de mundo ocidental [...]" (INGOLD, 1995, p. 9) como o são dependentes de suas culturas as outras definições - como as indígenas - em que a condição de pessoa não tem essa exclusividade, podendo ser estendida a animais, plantas, espíritos etc. No caso da farra do boi, cabe notar que mesmo o discurso dos defensores dos direitos dos animais apela para essa superioridade específica dos seres humanos, dada a sua elevada capacidade racional e, portanto, atribuindo aos homens uma série de responsabilidades como agentes morais efetivos. Nesse sentido, apesar de os animais não serem agentes morais (não podendo, por exemplo, ser responsabilizados por suas ações), não haveria porque excluí-los da condição de serem 
alvo da reflexão moral humana, ou seja, pacientes morais, em condição análoga a pacientes morais humanos como crianças pequenas e doentes mentais:

The fifth, and final, step in Regan's attempt to show that human moral agents have direct obligations with regard to non-human animals is his claim that at least some of the latter have the potential to be benefited or harmed by the actions of human moral agents which are not different in kind from those potentials in human moral patients. If the 'harm' principle applies to human moral patients, such as young children and the mentally enfeebled, then we cannot reasonably exclude non-human mammals with the appropriate degree of psychological complexity. Though these animals are not moral agents, and so cannot, for example, be held morally responsible for their actions, they belong, like humans whose agency is as yet undeveloped, or in certain ways impaired, to the category of moral patients. (BENTON, 1993, p. 81)

Enquanto o discurso contemporâneo de defesa dos direitos dos animais se dá em termos de uma clara oposição entre humanos e animais não-humanos, mesmo que para denunciar - e muitas vezes com razão os privilégios de exclusividade que apenas um dos lados possui em detrimento do outro, há que se reconhecer que esta é uma oposição formada a partir de fortes traços culturais. Ou, como disse Ingold, ela dependente de uma visão de mundo muito peculiar, aquela produzida pela cultura ocidental moderna. Mesmo assim, a dicotomia humanos versus animais não humanos é estendida, por alguns defensores dos animais, de forma a atingir um alcance global, abrangendo de uma só vez todas as espécies, toda a história e todas as regiões do planeta. De certa forma, ela projeta sobre as outras culturas o mesmo modo de existência que o Ocidente criou para si, com pressupostos próprios como o da separação natureza/cultura, ou humanos/não humanos.

Pode-se dizer, inclusive, que tal separação é antropocêntrica mesmo quando utilizada pelos conservacionistas ou em prol da defesa dos animais. Pois, em síntese, estes defensores refutam a tese de que o homem, na qualidade de ser racional, é o senhor da natureza e dos animais porque 
estes são desprovidos de consciência, para afirmar em seu lugar que o homem, como ser racional, deve cuidar da natureza e dos animais porque estes são desprovidos de consciência ${ }^{3}$. A condição de exclusividade permanece, adquirindo apenas um imperativo moral - que decorre da própria racionalidade. Como exemplo, para fins de contraste, de outras noções não ocidentais de existência, existem as sociedades indígenas amazônicas, para quem o discurso da conservação faz sentido apenas em parte, uma vez que seria "o outro lado da moeda" do discurso da exploração:

De fato, esses dois discursos sobre a Natureza têm, no fundo, premissas comuns que são radicalmente antagônicas às concepções indígenas. Exploração ou preservação da Natureza remetem ao mesmo pressuposto de uma Natureza-objeto, reificada como instância separada da sociedade e a ela subjugada. Ora, nada mais estranho que esta separação e este antropocentrismo para as cosmologias das sociedades amazônicas, que fazem do universo uma totalidade social regida por um complexo sistema de intercâmbios simbólicos entre sujeitos humanos e não-humanos, sistema do qual o xamanismo é a pedra de toque. (ALBERT, 2002, p. 257)

De acordo com Bruno Latour, a peculiaridade do Ocidente se deve a ao fato de que, ao conseguir realizar plenamente a distinção entre a esfera do social e a esfera da ciência, ou seja, entre cultura e natureza, o pensamento ocidental forjou a possibilidade de acesso direto à esta última, não mediado pelas imposições e distorções da primeira. Ao contrário dos demais povos do planeta, que só conseguem olhar para o mundo "através das lentes" de sua cultura, nós olharíamos para o mundo "como ele de fato é", uma vez que a ciência nos torna capazes de tanto, por meio de métodos precisos e de sua linguagem pura e objetiva. Dessa forma, seríamos constituídos por duas "grandes divisões", uma interna e outra externa:

\footnotetext{
${ }^{3}$ Assim, por exemplo, encontramos em um livro que defende enfaticamente os direitos dos animais a seguinte passagem: "O homem não é o ser supremo para o qual tudo o que existe lhe é subordinado; o homem não foi, não é e jamais será proprietário de qualquer Animal; o homem é o principal causador dos sofrimentos dos Animais; mas, o homem verdadeiramente racional e justo, querendo, encontrará a solução para adequar a vida de todos os seres do planeta" (RODRIGUES, 2010, p. 139).
} 
A Grande Divisão interior explica, portanto, a Grande Divisão exterior: apenas nós diferenciamos de forma absoluta entre a natureza e a cultura, entre a ciência e a sociedade, enquanto que todos os outros, sejam eles chineses ou ameríndios, zandés ou barouyas, não podem separar de fato aquilo que é conhecimento do que é sociedade, o que é signo do que é coisa, o que vem da natureza como ela realmente é daquilo que suas culturas requerem. Não importa o que eles fizerem, por mais adaptados, regrados e funcionais que possam ser, permanecerão eternamente cegos por esta confusão, prisioneiros tanto do social quanto da linguagem. Não importa o que nós façamos, por mais criminosos ou imperialistas que sejamos, escapamos da prisão do social ou da linguagem e temos acesso às próprias coisas através de uma porta de saída providencial, a do conhecimento científico. A partição interior dos não-humanos define uma segunda partição, desta vez externa, através da qual os modernos são separados dos pré-modernos. Nas culturas Deles, a natureza e a sociedade, os signos e as coisas são quase coextensivos. Em Nossa cultura, ninguém mais deve poder misturar as preocupações sociais e o acesso às coisas em si. (LATOUR, 1994, p. 99)

Além dos fundamentos filosóficos ocidentais que, não podem ser esquecidos, derivam de fundamentos teológicos, o próprio modo de vida moderno e suas relações de produção forneceram as condições para uma relação de dominação perante a natureza e os animais, transformando-os em "recursos naturais" - portanto passíveis de exploração, assim como de conservação. Esse processo histórico é também o de uma objetificação, simultânea a uma dessubjetivação, dos animais. No caso do pastoreio, a modernidade não deixou de avançar sobre um mundo que antes era mediado por relações de alteridade entre sujeitos - mesmo que desiguais. Se a domesticação de animais acontece desde a "Revolução Neolítica", há mais de 10 mil anos, traçando aí uma divisão entre o selvagem e o domés$t_{i c o}{ }^{4}$, ocorre que apenas no mundo industrializado e mecanizado o animal

\footnotetext{
4 "Deste complexo agro-pastoril surge uma dicotomização bastante radical entre o 'selvagem' e o 'domesticado', tanto para se referir à diferença entre campo cultivado e meio não humanizado, quando para se referir aos animais e plantas submetidos à ação do homem e aqueles não submetidos. 'Selvagem' vs. 'doméstico' passa a ser uma divisão tanto do espaço quanto dos elementos não-humanos deste espaço, instaurando um regime
} 
passa a ser visto como um tipo de "máquina" especializada, desprovido assim de qualquer elemento subjetivo:

Povos pastores, para Ingold [...], estabelecem com os animais relações calcadas na dominação. Como salienta o autor, não haveria chicotes, jugos e coleiras se não fosse identificada, por parte de quem os usa, uma mínima agência por parte dos animais. Ainda que já os reconhecendo como diferente do humano, a mobilização de animais no pastoreio tradicional não seria, portanto, a exploração de um recurso natural, mas um estatuto específico de apropriação do trabalho alheio. É somente com a mecanização intensiva do campo na modernidade - e o advento da tese cartesiana do animal-máquina - que a alteridade subjetiva do animal no mundo do pastoreio, sobre o qual incide uma relação pessoal, se torna uma alteridade objetiva, de tipo mecânico, própria ao mundo agroindustrial. (LEWGOY; SORDI, 2012, p. 148)

Seja na rotina e nas casas dos camponeses pobres ou na mitologia popular da época pré-moderna, não havia a distinção clara entre homens e animais que passou a existir após a Revolução Industrial. A linguagem do campo, em fins do século XVII, usava termos que faziam referência, simultaneamente, tanto a animais quanto a seres humanos, principalmente mulheres e crianças: kids, cubs, urchins, shrew, vixen etc (THOMAS, 2010, p. 138-139). Diferentemente da cisão moderna, compartilhava-se o mesmo universo moral, segundo Thomas:

Esse uso contínuo da analogia e metáfora animais no discurso cotidiano reforçou o sentimento de que homens e bichos habitavam o mesmo universo moral e que termos de louvor ou reprovação podiam ser aplicados de maneira intercambiável a qualquer deles. Por certo, essas analogias ainda são utilizadas hoje em dia, mas carecem do sentido imediato que tinha, no início do período moderno, graças à forte proximidade da vida animal. [...] No princípio do período moderno, o crescimento das cidades e da indústria começava a erodir essa familiaridade. (THOMAS, 2010, p. 139)

de descontinuidade dupla: entre os espaços e entre as espécies, dependendo da qualidade de sua relação com o elemento humano" (LEWGOY; SORDI, 2012, p. 148). 
Keith Thomas aborda o processo histórico com o qual se formou a atitude moderna em relação aos animais e à natureza em geral entre os britânicos, em que "[p]or volta de 1800, o antropocentrismo da era Tudor havia dado lugar a um estado de espírito muito mais confuso" (THOMAS, 2010, p. 426). A urbanização e a crescente dominação do campo afastaram os homens do convívio com animais de criação (gado) ao mesmo tempo em que a proximidade cada vez maior com animais de estimação levava a defender nestes a existência de certos traços "humanos". Isso fez com que surgisse uma espécie de bom gosto de classe média que tornava difícil de suportar cenas como a de um abatedouro mesmo que o consumo de carne, paradoxalmente, crescesse entre a população.

É justamente esse bom gosto urbano nascente que se viu agredido pelo ritual da farra do boi no litoral de Santa Catarina a partir de fins dos anos 1970, quando a região passa por um acelerado processo de urbanização e recebe populações migrantes de outras regiões mais desenvolvidas do país (como Rio de Janeiro, São Paulo, Rio Grande do Sul). Esses migrantes, com maior poder aquisitivo, passam a adquirir as terras das famílias nativas para ali construir suas casas, entrando em contato com a farra do boi após ingressarem em seu território tradicional. Como expôs Eugênio Lacerda, a farra caracteriza-se por não caber nos padrões ditos "civilizados" da sociedade moderna:

Na verdade, o problema todo é que o boi solto está situado no campo do excesso, não da norma. É uma transgressão, uma extravagância [malcomportada], capaz de escandalizar a moral vigente, urbana, educada, asséptica. Ora, o boi rompe cercas, provoca o instinto, ataca, bufa, não quer ser domado. O pescador quer a correria, o desafio, a galhofa, procura superar as fronteiras do tempo hodierno, enfim diverge da ordem natural das coisas. (LACERDA, 1993, p. 119)

Em vez de proceder à lógica moderna de manter as coisas em seu devido lugar, separando homens e animais, cidade e natureza, terrenos particulares e espaços públicos, a farra do boi procede à dissolução desses limites. Muito dessa dissolução dá-se por causa da condição de jejum e 
embriaguez ${ }^{5}$ na qual a ela ocorre, própria de festividades sacras como é o caso desse rito sacrificial em que o boi é imolado. É por isso que ela só pode ser vista como transgressora, como um abuso injustificado, uma confusão perigosa que faz esquecer - mesmo que brevemente - os lugares de cada um, homens, deuses e animais.

\section{Sensibilidades Morais e Jurídicas}

Para Keith Thomas (2010, p. 424), a “[...] ocultação dos matadouros ao olhar público tornou-se um recurso necessário para evitar um choque excessivamente forte entre a realidade material e as sensibilidades privadas". A sociedade moderna, ao urbanizar-se, afastava-se cada vez mais do mundo natural, que passava então a ser idealizado e a alimentar fantasias:

Para os adultos, os parques naturais e as áreas preservadas cumprem uma função que não é diferente da que os bichos de pelúcia têm para as crianças; são fantasias que cultuam os valores mediante os quais a sociedade, como um todo, não tem condições de viver. (THOMAS, 2010, p. 426)

Ao que parece, outra cisão moderna se estabeleceu com a civilização industrial: passamos a habitar um mundo de indivíduos sensíveis em relação ao mundo natural (pelo menos a algumas de suas espécies), mas que vivem em uma sociedade que se constitui em aberta oposição à natureza, sem que isso pareça uma grande contradição:

Diz-se, com demasiada frequência, que as sensibilidades e a moral são mera ideologia: uma racionalização conveniente do mundo tal

\footnotetext{
${ }^{5}$ Assim sugere Rafael de Menezes Bastos (1993, p. 24, grifos no original): "A embriaguez e o jejum fabricam no farrista um outro tipo de consciência - que não é a da vida normal. Uma consciência continuamente desejante, que vai estabelecer a ética e a estética das relações homem-touro para muito longe de toda e qualquer rotinização tecno-lógica. Tal rotinização - que os desenha como comedor e comida óbvios - é recusada, a Farra, assim cancelando o exílio mútuo entre homem e natureza, adiando-lhes até os limites máximos e sob a ética e a estética da invulnerabilidade - sinais da divinação de ambos -, a transformação em fezes, poluição essencial".
} 
como ele é. Mas, no início do período moderno, a verdade era quase o oposto, pois, por uma lógica inexorável, emergiram aos poucos atitudes face ao mundo natural essencialmente incompatíveis com a direção em que se movia a sociedade inglesa. O crescimento das cidades conduziu a um novo anseio pelo campo. O progresso da lavoura fomentou um gosto por ervas daninhas, montanhas e natureza não dominada. A recém-descoberta segurança diante dos animais selvagens produziu um empenho cada vez maior em proteger aves e conservar as criaturas selvagens no seu estado natural. A independência econômica face à energia animal e o isolamento urbano em relação aos bichos nutriram atitudes difíceis, senão impossíveis, de se conciliar com a exploração dos animais que dava o sustento à maior parte das pessoas. Doravante, uma visão cada vez mais sentimental dos animais enquanto bichos de estimação e objetos de contemplação iria acomodar-se mal com a sombria realidade de um mundo no qual a eliminação das "pestes" e a criação de animais para abate ia-se tornando cada dia mais eficiente. (THOMAS, 2010, p. 425)

Ao falar da formação da sensibilidade moral do homem moderno perante a natureza, Thomas abre espaço para que pensemos na farra do boi como uma "polêmica" causada pelo conflito de sensibilidades morais. É sobre essas sensibilidades que se formam o sentimento de justiça, ou aquilo que Geertz chamou de sensibilidade jurídica ${ }^{6}$. As diferentes sensibilidades jurídicas mostram que o direito tem bases culturais que norteiam sua relação com o mundo real, seja traçando sua própria definição seja estabelecendo as formas de sua aplicação em casos concretos.

Lawrence Rosen, por sua vez, pretende demonstrar que o direito é inseparável dos demais domínios da vida cultural e social, uma vez que a criação de significado jurídico se dá dentro de um meio cultural mais amplo. O direito, portanto, está dentro de um sistema de significados que

\footnotetext{
6 "E outros mercados, outros Anschauungen. Aquele sentido de justiça que mencionei acima - a que chamarei [...] de sensibilidade jurídica - é, portanto, o primeiro fator que merece a atenção daqueles cujos objetivos é falar de uma forma comparativa sobre as bases culturais do direito. Pois essas sensibilidades variam, e não só em graus de definição; também no poder que exercem sobre os processos da vida social, frente a outras formas de pensar e sentir" (GEERTZ, 2009, p. 261).
} 
“dá sentido à vida das pessoas". Mais do que para restaurar a ordem, o direito serve como um campo de compartilhamento dos termos pelos quais as pessoas travam relações e estabelecem discordâncias, fornecendo um senso de "ordem" que ultrapassa a esfera dos tribunais. O que a antropologia jurídica permitiu ver em "sociedades sem escrita", agora estaria se tornando visível em nossa própria sociedade. Como aponta Rosen (2006, p. 23):

Like every other aspect of a culture, law lives in a place that is not solely of its own making. As we open up the idea of law to intersect those other domains where we fabricate the categories of our everyday experience, we open up the possibility not just for an enlarged sense of how law draws upon all the other domains of life for its own ends: We also see how cultures embrace both the order law seeks and the open-endedness that life requires to fashion a world that, for those who entangle their lives in its terms, gives order and flexibility to individuals and groups alike.

Assim, ao submeter a noção de direito a uma abertura, como Rosen propõe, percebe-se que as questões jurídicas são também questões culturais. E, conforme eu proponho, em alguns casos como no da farra do boi, o inverso também ocorre: certas "questões culturais" trazem consigo uma dimensão jurídica. O que é visto por alguns como conflito de valores culturais é também um conflito jurídico, no sentido de que existem diferentes sensos de justiça - ou diferentes definições de certo e errado - em jogo. A caracterização da farra do boi como prática violenta, portanto, choca-se com as concepções nativas dos farristas a respeito da própria violência, assim como com as definições nativas do que seja agressão ilegítima. $\mathrm{Na}$ introdução de sua coletânea, Rafael de Menezes Bastos expõe as razões do apoio dos antropólogos à prática, por meio da aprovação de uma moção de apoio pela Associação Brasileira de Antropologia em 1990:

Os apresentadores da moção - eu, entre eles - procuraram, durante a assembléia, enfatizar que a festa, trata-se de um ritual que constitui a violência (sim, pois ela não é óbvia) - isolando a brincadeira da judiaria, respectivamente violências legítima e ilegítima - é o espaço sócio-cultural por excelência competente, entre os Ilhéus, 
de sua administração e controle. Note-se que durante a Farra a eventual manifestação de judiaria contra o animal é imediatamente coibida pelos próprios farristas, a idiossincrática explosão de violência não constituindo, assim, padrão da festa (tanto quanto, por exemplo, no Carnaval). (BASTOS, 1993, p. 12, grifos no original)

A percepção dessa complexidade leva a questão da farra do boi para muito além da discussão entre cultura e meio-ambiente interna à Constituição. Ocorre que este é um interesse existente entre antropólogos do direito, mas praticamente inexistente - e sem lugar para ser reconhecido - no meio jurídico. Para chegar a essas diferentes sensibilidades jurídicas, deve-se cuidar com as armadilhas tanto do etnocentrismo quanto do relativismo absoluto, ou como diz Luís R. Cardoso de Oliveira (2010, p. 466):

Isto significa que para apreender a sensibilidade jurídica ou senso de justiça em tela o pesquisador deve levar a sério as pretensões de validade dos "nativos" quanto ao caráter equânime do procedimento adotado e dos respectivos encaminhamentos. Tal esforço deve desembocar no convencimento do pesquisador quanto à razoabilidade destas pretensões ou em questionamentos razoáveis quanto às mesmas, sempre com o cuidado de evitar, num só tempo, o etnocentrismo (autoritário e excludente por definição) e o relativismo-niilista, que não consegue aceitar a capacidade argumentativa do interlocutor e as possibilidades de fundamentação de suas justificativas.

Como o julgador não precisa ter os mesmos cuidados do que o antropólogo - sendo indiferente, para os efeitos de sua decisão, se houve ou não algum esforço de compreensão das "pretensões de validade" dos envolvidos - a postura mais comum a ser encontrada em julgamentos que envolvam questões culturais é a etnocêntrica. Trata-se da imposição dos valores expressos no conteúdo da lei, ou do que a interpretação majoritária diz que a lei expressa, em situações e contextos que nem sempre foram cuidadosamente compreendidos. Tal constatação deve-se ao fato de que em pouquíssimos ou nenhum momento de sua formação os operadores do direito recebem qualquer treinamento para lidar com a alterida- 
de de saberes e diferentes noções de existência - lacuna que vem sendo preenchida aos poucos com o ensino, nos cursos de direito, da disciplina Antropologia Jurídica.

\section{A Turba Ensandecida e a Turma Esclarecida}

Um exemplo da diferença entre as exigências éticas e metodológicas do olhar antropológico e os mecanismos jurídicos de resolução de conflito pode ser encontrado no julgamento da farra do boi pelo STF. É o que se depreende dos votos do acórdão que pôs termo à Ação Civil Pública n. 023.89.0300082-0, de autoria de uma entidade civil chamada Associação Amigos de Petrópolis Patrimônio Proteção aos Animais e Defesa da Ecologia (APANDE), que chegou à Suprema Corte por meio do Recurso Extraordinário n. 153.531-8 Santa Catarina, julgado em 3 de junho de 1997. A Segunda Turma, que julgou o Recurso, formada por cinco ministros, decidiu no Acórdão pela proibição da farra do boi por maioria de três votos a um (um ministro, Nelson Jobim, ausentou-se justificadamente) considerando-a prática "necessariamente cruel e violenta" (STF, RE 153531-8/97, relatório do min. Francisco Rezek, fl. 395).

Ocorre que já no voto do relator, ministro Francisco Rezek, encontra-se uma fundamentação fática que não faz menção a provas ou a depoimentos - uma vez que o reexame de provas não é permitido em sede de Recurso Extraordinário ${ }^{7}$ - mas faz menção à "notoriedade" do caso. E tal menção é feita numa linguagem hiperbólica:

[...] os fatos são de uma gritante notoriedade, que ultrapassa nossas fronteiras; poucas coisas são tão tristemente notórias quanto o ritual da chamada 'farra o boi' e o que nela acontece no litoral catarinense a cada ano. (STF, RE 153531-8/97, voto do min. Francisco Rezek, fl. 399)

Dessa forma, o ministro-relator se vê tendo acesso direto à verdade dos fatos que, notórios, seriam perceptíveis a qualquer um. E assim con-

${ }^{7}$ Conforme prevê a Súmula 279 do STF, "Para simples reexame de prova não cabe recurso extraordinário". 
segue identificar a crueldade intrínseca e a violação à Constituição perpetradas pela farra do boi:

Em que consiste essa prática, o país todo sabe. Poupei o Tribunal, como é de meu feitio, de ler determinadas peças do processo em nome dessa notoriedade. Há coisas repulsivas aqui narradas por pessoas da sociedade catarinense, narradas por sacerdotes de Santa Catarina e por instituições comprometidas com o primado da Constituição no que se refere à proibição da crueldade para com os animais. [...] Não posso ver como juridicamente correta a ideia de que em prática dessa natureza a Constituição não é alvejada. Não há aqui uma manifestação cultural com abusos avulsos; há uma prática abertamente violenta e cruel com animais, e a Constituição não deseja isso. (STF, RE 153531-8/97, voto do min. Francisco Rezek, fl. 400)

Os outros dois votos favoráveis ao Recurso da APANDE seguem o tom do voto do relator, de que a interpretação dos fatos é unívoca. O min. Marco Aurélio, por sua vez, refere-se aos praticantes da farra do boi da seguinte forma: "[...] uma turba ensandecida que vai atrás do animal para procedimentos que estarrecem" (STF, RE 153531-8/97, voto do min. Marco Aurélio, fl. 414). Ao apresentar as fontes de embasamento de sua drástica definição, contudo, o que nos mostra é que assistiu às cenas na televisão: "O Jornal da Globo mostrou um animal ensangüentado e cortado invadindo uma residência e provocando ferimento em quem se encontrava no interior" (STF, RE 153531-8/97, voto do min. Marco Aurélio, fl. 414). A brevidade com que se refere à notícia, única alusão que faz à farra do boi, contrasta com a veemência de sua declaração. Sem falar que talvez não se encontre nada mais antagônico ao dever antropológico de "levar à serio o ponto de vista dos nativos" do que o retrato alucinado feito pelo ministro, que não deixa de lembrar os primeiros relatos sobre costumes dos "povos primitivos" feitos por europeus no século XIX".

${ }^{8}$ Já dizia Malinowski ([1922] 1978, p. 24), na introdução de seu clássico Argonautas: "Foi-se o tempo em que se aceitavam relatos nos quais o nativo aparecia como uma caricatura infantil do ser humano. Relatos desse tipo são falsos - e, como tal, a ciência os rejeita inteiramente. O etnógrafo de campo deve analisar com seriedade e moderação todos os fenômenos que caracterizam cada aspecto da cultura tribal sem privilegiar 
Essa parece ser a grande diferença entre a abordagem antropológica e a do julgador. Ou, como disse Roberto Kant de Lima, sobre a dessemelhança entre o conhecimento científico e o direito brasileiro, no primeiro caso as divergências são resolvidas pelos próprios defensores de teses opostas, que devem demonstrar o quão são convincentes seus argumentos, sem recorrer à autoridade de um terceiro: "[...] é a autoridade do argumento, e não o argumento de autoridade, que define o destino da disputa" (KANT DE LIMA, 2012, p. 36). Para Kant de Lima (2012), a proliferação de manuais em nosso meio jurídico congelaria a vivacidade do pensamento e impediria a crítica e a reflexão. A antropologia, pelo contrário, não abriria mão da relação com a pesquisa empírica, construindo-se na interlocução com os envolvidos:

[...] relevante é o papel que a pesquisa empírica assume na produção do conhecimento nas ciências naturais e sociais, por oposição àquele que tem na produção do conhecimento jurídico. Na antropologia, em especial, o conhecimento é construído pela interlocução com os atores que participam do campo estudado, eles mesmos coprodutores desse conhecimento científico. Já no campo jurídico, em que as verdades são reveladas e, até mesmo, reificadas, como é o caso da "verdade real", a empiria não tem papel relevante, a não ser para confirmar o que já se sabe. (KANT DE LIMA, 2012, p. 37)

O terceiro voto pelo provimento do Recurso foi do ministro Néri da Silveira, que presidia a Sessão. O magistrado inicia seu voto afirmando que a "matéria está amplamente debatida" (STF, RE 153531-8/97, voto do min. Néri da Silveira, fl. 415), apesar de o voto anterior ter sido dado em apenas duas páginas e o seu próprio ter cinco. Ali, afirma que não cabe àquela ocasião reexaminar os fatos já anteriormente considerados em outras decisões (que haviam sido desfavoráveis aos demandantes da

aqueles que lhe causam admiração ou estranheza em detrimento dos fatos comuns e rotineiros. Deve, ao mesmo tempo, perscrutar a cultura nativa na totalidade de seus aspectos". A pertinência desta citação, que recorre ao fundador do método antropológico da observação participante, decorre menos da proximidade, entre as "tribos" por ele estudadas e os habitantes do litoral de Santa Catarina que praticam a farra do boi, do que da semelhança de tratamento que estas populações receberam dos setores "esclarecidos" da sociedade dominante. 
proibição da farra do boi), mas que eles seriam "visualizados na perspectiva do ordenamento constitucional" (STF, RE 153531-8/97, voto do min. Néri da Silveira, p. 415), no que passa a contrapor artigos da Constituição, sobretudo o 215 com o 225 . O ministro então nos apresenta uma definição de cultura do ponto de vista jurídico, ou seja, como um direito resguardado pela Constituição:

A cultura pressupõe desenvolvimento que contribua para a realização da dignidade da pessoa humana e da cidadania e para a construção de uma sociedade livre, justa e solidária. Esses valores não podem estar dissociados da compreensão do exercício dos direitos culturais e do acesso às fontes da cultura nacional, assim como previsto no art. 215 suso transcrito. Essa é uma vertente de entendimento da matéria sob o ponto de vista constitucional. (STF, RE 153531-8/97, voto do min. Néri da Silveira, fl. 417)

O direito à cultura, assim, passa a ser visto não apenas como algo contraposto ao direito ambiental, mas é também atrelado a outros valores, como a cidadania e a dignidade humana. Se a cultura é vista como um direito, isso significa por um lado que ela deve ser protegida; mas por outro, tal visão estabelece que não é qualquer prática que atende às condições apontadas pelo ministro Néri da Silveira sobre o que pressupõe a cultura. Isso acaba levando à constatação de que, aos olhos do direito, nem tudo é cultura, pois nem tudo atende a esses pressupostos - o que vai muito além de dizer que o argumento da "cultura" não pode ser aceito como justificativa para qualquer prática, o que é compreensível sobretudo quando se constata comportamento cruel.

$\mathrm{O}$ único voto contrário à proibição total da farra do boi partiu do ministro Maurício Corrêa, em seu voto-vista. Com 11 páginas, foi o único a fazer referência a estudos e livros publicados sobre o assunto, citando ao menos duas coletâneas de artigos e uma "Comissão de Estudos da Farra do Boi”. É o único voto, também, a citar trechos da decisão anterior, do Tribunal de Justiça de Santa Catarina, assim como somente ele aponta as ações tomadas pelo Estado de Santa Catarina para coibir atos violentos durante os eventos. Para o ministro Maurício Corrêa, não seria impossível a conciliação dos valores prescritos pela Constituição: 
Não há antinomia na Constituição Federal. Se por um lado é proibida a conduta que provoque a extinção de espécies ou submetem os animais à crueldade, por outro lado ela garante e protege as manifestações das culturas populares, que constituem patrimônio imaterial do povo brasileiro. (STF, RE 153531-8/97, voto do min. Maurício Corrêa, fl. 406)

Logo, a farra do boi seria mais uma questão de averiguar os "casos de polícia" existentes, como a ocorrência de maus-tratos, do que uma questão constitucional ${ }^{9}$ a ser debatida entre os doutos ministros do STF. Para Maurício Corrêa, a proibição dessa prática cultural em uma decisão de Recurso Extraordinário seria extrapolar as capacidades da Corte em verificar o que ocorre na prática:

Ora, subverter um preceito constitucional que estabelece a vedação da prática de crueldade a animais - por ser regra geral -, para o fim de produzir efeitos cassatórios do direito do povo do litoral catarinense a um exercício cultural com mais de duzentos anos de existência, parece-me que é ir longe demais, tendo em vista o sentido da norma havida como fundamento para o provimento do recurso extraordinário. Não vejo como, em sede extraordinária, se aferir que as exacerbações praticadas por populares na realização desse tipo de cultura, que implicam em sanções contravencionais, possam ser confundidas com essa prática cultural que tem garantia constitucional. Isso é uma questão de polícia e não de recurso extraordinário. (STF, RE 1535318/97, voto do min. Maurício Corrêa, fl. 411)

A recusa do ministro Maurício Corrêa em utilizar a "sede extraordinária" para proferir uma decisão com "efeitos cassatórios de direito" é compreensível. O Recurso Extraordinário tem sua origem como mecanismo de defesa dos direitos fundamentais, e é assim que outros países

\footnotetext{
${ }^{9} \mathrm{O}$ nome alude à condição para se levar um recurso à competência do STF, daí o fato de ser o recurso chamado de "Extraordinário". Conforme prevê a Constituição: "Art. 102 Compete ao Supremo Tribunal Federal, precipuamente, a guarda da Constituição, cabendo-lhe: III - julgar, mediante recurso extraordinário, as causas decididas em única ou última instância, quando a decisão recorrida: a) contrariar dispositivo desta Constituição", entre outras competências do Tribunal (BRASIL, 1988).
} 
o aplicam. Isso significa dizer que tal recurso, originariamente, tinha a função de proteger aqueles direitos do indivíduo contra os quais o Estado não tem legitimidade para impor proibições ${ }^{10}$. São direitos que, segundo a doutrina, visam a proteger o cidadão contra as arbitrariedades das autoridades estatais, também conhecidos como direitos negativos, pois limitam o poder do Estado. O recurso à Suprema Corte, portanto, seria a última tentativa de fazer valer essa proteção. Por alguma razão, no entanto, o artigo 102 da Constituição ampliou o leque de competência do Recurso Extraordinário para todo e qualquer dispositivo constitucional. Dessa forma, esse deixou de ser um instrumento de defesa do cidadão para se tornar, como no caso de que trato neste ensaio, em instrumento de decisão do Estado. De acordo com Gilmar Mendes (1999, p. 416),

[...] ao contrário do que se verifica em outras ordens constitucionais, que limitam, muitas vezes, o recurso constitucional aos casos de afronta aos direitos fundamentais, optou o constituinte brasileiro por admitir o cabimento do recurso extraordinário contra qualquer decisão que, em única ou última instância, contrariar a Constituição. [...] Portanto, a admissibilidade do recurso constitucional não está limitada, em tese, a determinados parâmetros constitucionais, como é o caso da Vervassungsbeschwerde na Alemanha (Lei Fundamental, art. 93, n. $4^{\circ}$ ), destinada basicamente à defesa dos direitos fundamentais.

Devo notar que esta minha análise, além de estar longe de uma compreensão unânime do caso, e mais longe ainda da interpretação majoritária das normas, não pode exercer qualquer interferência sobre uma decisão já tomada há mais de vinte anos e sobre a qual não cabe nenhum recurso. Para que se dar ao trabalho de voltar ao caso da farra do boi, então, já que esta discussão é inútil em termos processuais? Ocorre que meu interesse no caso é sobretudo antropológico, não olhando para ele com os olhos de um advogado. A análise de decisões judiciais já foi apontada como de grande valia para o estudo de antropologia jurídica:

\footnotetext{
${ }^{10}$ Os direitos fundamentais, na Constituição, estão concentrados no artigo $5^{\circ}$ e seus 78 incisos, não se limitando aos que estão aí citados.
} 
A vantagem de mudar o foco da análise, passando das normas para as decisões, através da radicalização de questões de adequação, é que, assim procedendo, pode-se flexibilizar associações estritas entre situações típico-ideais e casos específicos de conflito. Abrindo-se novas possibilidades de superação de definições/interpretações normativas cristalizadas, sem que se assuma o compromisso de tomar uma posição sobre a legitimidade das normas em si mesmas, e evitando-se as dificuldades respectivas. (CARDOSO DE OLIVEIRA, 1992, p. 40)

Reconheço, entretanto, uma diferença de propósito com o trecho acima citado. Se Cardoso de Oliveira propôs uma mudança de foco "[...] passando das normas para as decisões", ele o fez pensando "[...] no contexto das preocupações antropológicas com a compreensão de diferentes culturas" (CARDOSO DE OLIVEIRA, 1992, p. 40). Foi ao retomar a análise do famoso caso de Regreg, utilizado por Geertz como exemplo de uma "sensibilidade jurídica balinesa", que Cardoso de Oliveira demonstrou a insuficiência de uma mera análise das normas descolada de sua aplicação na solução de casos concretos. O que proponho, e de certa forma acho que fiz, é a análise antropológica de uma decisão judicial do Poder Judiciário brasileiro, o que envolve considerar a análise não-antropológica que os membros do judiciário realizam sobre os eventos. Isso levaria a um último dilema ético: como levar a sério o ponto de vista do nativo se este nativo se sobressai exatamente pelas consequências que a sua forma de ver o mundo produz na vida de outras pessoas (e de outros animais)? Não se tratam, portanto, apenas de "visões de mundo", mas de ações sobre ele, de produções de efeito, de decisões que irão balizar o comportamento do Estado perante as mais diversas práticas sociais e culturais.

\section{Conclusão}

O caso aqui trazido é apenas um exemplo - embora nada fortuito, uma vez que a farra continua suscitando debates sobre o certo e o errado e produzindo, na vida real, inúmeros conflitos, ações policiais, prisões e apreensões de gente e de bois, entre outras mobilizações do aparato 
repressivo estatal - de como se podem comparar diferentes sensibilidades jurídicas no Brasil de hoje e de como a antropologia encara esse tipo de situação, em contraste com a postura geral dos julgadores, em relação a uma alteridade cultural bastante específica como esta. Sem querer fazer deste artigo uma defesa explícita de um ou outro lado (contra ou a favor) do debate em torno da farra do boi, busquei jogar luz sobre alguns elementos que me pareceram contraditórios na opinião geral - e, em último caso, vencedora, uma vez que contida nos votos da maioria dos ministros da Turma do STF que encerrou a questão - que toma como dadas e universais algumas divisões que, justamente por estarem vinculadas ao pensamento ocidental moderno e urbano, deixam de operar com sua eficácia plena em fenômenos culturais como o da farra do boi nas comunidades do litoral de Santa Catarina.

Sugere-se que as dificuldades no tratamento da questão pela Suprema Corte não se devem a uma "distância cultural" insuperável ente julgadores e farristas, mas estão associadas à desobrigação, por parte dos primeiros, de buscar compreender aquilo que a antropologia chama de "o ponto de vista dos nativos", e que Geertz chamaria de uma "sensibilidade jurídica" específica. Não se trata, contudo, de cair num relativismo niilista e absoluto, que impede qualquer comunicação e comparação entre os diversos saberes locais e suas pretensões universalistas. Como lembra o próprio Geertz (2009, p. 249), tanto o direito quanto a etnografia seriam incumbidos da "tarefa artesanal de descobrir princípios gerais em fatos paroquiais".

O que o caso da farra do boi traz de peculiar, portanto, é não somente um exemplo de como aquilo que chamamos de cultura popular continua sendo algo extremamente diverso e capaz de suscitar escândalos ou simpatias aos olhos externos, mas seu potencial de mobilizar categorias (cultura, meio ambiente, crueldade, direitos, entre outras) que falam abertamente às nossas próprias concepções de justiça, natureza, costume, entre outras, apresentando outros olhares e desafios capazes de alargá-las. Isso, é claro, desde que estejamos dispostos a ouvir. 


\section{Referências}

ALBERT, Bruce. O ouro canibal e a queda do céu. Uma crítica xamânica da economia política da natureza (Yanomami). In: ALBERT, B.; RAMOS, A. (org). Pacificando o branco: cosmologias do contato no norte amazônico. São Paulo: UNESP, 2002. p. 239-270.

BASTOS, Rafael José de Menezes (org.). Dionísio em Santa Catarina: ensaios sobre a farra do boi (Introdução). Florianópolis: EdUFSC, 1993.

BENJAMIN, Walter. O anjo da história. Organização e tradução de João Barrento. 2. ed. Belo Horizonte: Autêntica, 2013.

BENTON, Ted. Natural relations: ecology, animal rights \& social justice. London: New York: Verso, 1993.

CARDOSO DE OLIVEIRA, Luís R. Comparação e interpretação na antropologia jurídica, Anuário Antropológico/89, Rio de Janeiro: Tempo Brasileiro, p. 23-45, 1992.

CARDOSO DE OLIVEIRA, Luís R. A dimensão simbólica dos direitos e a análise de conflitos. Revista de Antropologia, São Paulo, USP, v. 53, n. 2, p. 451-473, 2010.

DUMONT, Louis. O individualismo: uma perspectiva antropológica da idade moderna. Tradução Álvaro Cabral. Rio de Janeiro: Rocco, 1985.

FLORES, Maria Bernardete Ramos. A farra do boi: palavras, sentidos, ficções. 2. ed. Florianópolis: EdUFSC, 1998.

GEERTZ, Clifford. O saber local: fatos e leis em uma perspectiva comparativa. In: GEERTZ, Clifford. O saber local: novos ensaios em antropologia interpretativa. Petrópolis: Vozes, 2009. p. 249-356.

HOBBES, Thomas. Leviatã (ou matéria, forma e poder de um Estado eclesiástico e civil) [1651]. In: KIRSCHKE, Paulo J. (org.). O contrato social, ontem e hoje. São Paulo: Cortez, 1993. p. 61-80.

INGOLD, Tim. Humanidade e animalidade. Revista Brasileira de Ciências Sociais, [s.l.], v. 28, junho de 1995. 
KANT DE LIMA, Roberto. Antropologia jurídica. In: LIMA, Antonio Carlos de Souza (coord.). Antropologia e direito: temas antropológicos para estudos jurídicos. Rio de Janeiro; Brasília: Contra Capa; LACED; Associação Brasileira de Antropologia, 2012. p. 35-54.

LACERDA, Eugênio Pascele. Farra do boi: a história e a polêmica. In: BASTOS, Rafael José de Menezes (org.). Dionísio em Santa Catarina: ensaios sobre a farra do boi. Florianópolis: EdUFSC, 1993. p. 115-123.

LATOUR, Bruno. Jamais fomos modernos: ensaio de antropologia simétrica. Rio de Janeiro: Ed. 34, 1994.

LEWGOY, Bernardo; SORDI, Caetano. As guerras da carne: o consumo carnívoro, seus defensores e críticos. In: STEIL, Carlos A.; CARVALHO, Isabel C. de M. (org.). Cultura, percepção e ambiente: diálogos com Tim Ingold. São Paulo: Terceiro Nome, 2012. p. 137-151. Coleção antropologia hoje.

\section{MALINOWSKI, Bronislaw. Argonautas do Pacífico Ocidental: um} relato do empreendimento e da aventura dos nativos nos arquipélagos da Nova Guiné melanésia. Prefácio de Sir James Frazer; traduções de Anton P. Carr e Lígia Aparecida Cardieri Mendonça; revisão de Eunice Ribeiro Durham. 2. ed. São Paulo: Abril Cultural, 1978.

MENDES, Gilmar Ferreira. Direitos fundamentais e controle de constitucionalidade: estudos de direito constitucional. 2. ed. rev. e ampl. São Paulo: Celso Bastos Editor; Instituto Brasileiro de Direito Constitucional, 1999.

RODRIGUES, Danielle Tetü. O direito \& os animais: uma abordagem ética, filosófica e normativa. 2. ed. Curitiba: Juruá, 2010.

ROSEN, Lawrence. Law as culture: An invitation. Princeton, New Jersey: Princeton University Press, 2006.

THOMAS, Keith. O homem e o mundo natural: mudanças de atitude em relação às plantas e aos animais (1500-1800). Tradução João Roberto Martins Filho. São Paulo: Companhia das Letras, 2010. 
João Francisco Kleba Lisboa é doutor em Antropologia Social pela Universidade de Brasília. Mestre e Graduado em Direito pela Universidade Federal de Santa Catarina.

E-mail: jfklisboa@gmail.com

Endereço profissional: Rua Schiller, n. 555, ap. 92, Alto da XV, Curitiba, PR. CEP: 80050-901.

ORCID 0000-0002-2443-7050

CV: http://lattes.cnpq.br/0171811084621459 